\title{
Karyotype and Fluorescence In Situ Hybridization Analysis of 15 Lilium Species from China
}

\author{
Guangxin Liu \\ College of Biology and the Environment, Co-Innovation Center for the Sustainable Forestry in \\ Southern China, Nanjing Forestry University, Nanjing 210037, China \\ Xiaoling Zhang, Yue Lan, and Haoyang Xin \\ College of Forestry, Co-Innovation Center for the Sustainable Forestry in Southern China, Nanjing \\ Forestry University, Nanjing 210037, China \\ Fengrong Hu \\ College of Landscape Architecture, Nanjing Forestry University, Nanjing 210037, China
Zhuhua Wu, Jisen Shi, and Mengli Xi ${ }^{1}$
College of Forestry, Co-Innovation Center for the Sustainable Forestry in Southern China, Nanjing
Forestry University, Nanjing 210037, China

Additional Index words. Lilium, chromosome, 45S rDNA, gene location

\begin{abstract}
Karyotype comparison and fluorescence in situ hybridization (FISH) were conducted to analyze the wild Lilium species distributed in China. The karyotype results revealed that all species except Lilium lancifolium $(2 n=3 X=36)$ were diploid and had two pairs of metacentric or submetacentric chromosomes. The karyotypes of all species are similar. FISH analysis revealed that there are 5-12 45S rRNA gene loci dispersed on the chromosomes of the 14 diploid species, and $1545 \mathrm{~S}$ rRNA gene loci were detected in the triploid species $L$. lancifolium. Most of the FISH signals were detected on the long arms and the centromeric regions. Three samples of $L$. brownii [Hubei, China (lat. $31^{\circ} 28^{\prime} \mathrm{N}$, long. $110^{\circ} 23^{\prime} \mathrm{E}$ ); Liaoning, China (lat. $40^{\circ} 07^{\prime} \mathrm{N}$, long. $124^{\circ} 19^{\prime} \mathrm{E}$ ); and Guangxi, China (lat. $25^{\circ} 06^{\prime} \mathrm{N}$, long. $107^{\circ} 27^{\prime} \mathrm{E}$ )] showed very similar chromosome patterns in both the karyotype and the FISH analyses, further demonstrating that these samples belonged to the same species. $L$. brownii is widely distributed in China from latitude $25^{\circ} 06^{\prime} \mathrm{N}$ to $40^{\circ} 07^{\prime} \mathrm{N}$, indicating that it is highly adaptable to the environment.
\end{abstract}

Lilies (Lilium sp.) have substantial ornamental, medicinal, and edible value and are the most important cut flowers worldwide (Long et al., 1999). The genus Lilium is native to the Northern Hemisphere, including Asia, Europe, and North America, and it includes $\approx 100$ species (Anderson, 1986; McRae, 1998). These species have been classified by different authors into 5-10 sections or subgenera (Comber, 1949; De Jong, 1974; Endlicher, 1836; Mabberley, 1990). All species of Lilium show the same basic chromosome number $(x=12)$, similar karyotype features, and a very large genome size (Zonneveld et al., 2005). Karyotype characteristics for most Lilium species have been examined (Stewart, 1947), and two large metacentric chromosome pairs and 10 subtelocentric or telocentric pairs are always present.

China possesses the greatest Lilium diversity in the world, with $\approx 55$ species, 36 of which are unique to China (Long et al., 1999). Some of these have been used to breed new cultivars. For example, the 'Olympic', 'Lady Byng', and 'Queen Charlotte', which are still grown today, were all selected from Chinese species (Long et al., 1999). As the

Received for publication 13 Mar. 2017. Accepted for publication 19 June 2017. This work was supported by the Jiangsu Provincial Key Basic Research Foundation for Universities (16KJA220001), the National Natural Science Foundation of China (31670603), and a project funded by the Priority Academic Program Development of Jiangsu Higher Education Institutions.

${ }^{1}$ Corresponding author. E-mail: ximenglinjfu@126.com. orange flowered member of the Lilium genus, L. henryi from Hubei, China, has received considerable attention for a long time. Many cultivars, including the famous 'Black Beauty', were all selected from the hybrids of $L$. henryi with other species. 'Enchantment' and 'Connecticut King' are considered descendants part of the ancestry of L. lancifolium. $L$. regale is an important breeding Lilium species that has been widely grown. L. pumilum is famous for its resistance to Fusarium and Botrytis cinerea (Long et al., 1999). Two American cultivars, 'Nepera' and 'City Lights', were bred from hybrids of $L$. tsingtauense. Thus, Chinese Lilium plants have made an important contribution to global breeding of the genus (Long et al., 1999). To further explore, use, and protect these resources, several major projects have been dedicated to their collection and in vitro preservation (Chen et al., 2007; Zhang et al., 2004) of Lilium germplasm in three regions of China (southwest, northwest, and northeast China). Three southwestern provinces, Sichuan, Yunnan, and Tibet, form the region with the broadest population distribution of the genus Lilium, containing $\approx 36$ species (Wang and Tang, 1980; Wu et al., 2006). Four northwestern provinces, Shanxi, Gansu, Hubei, and Henan, contain $\approx 14$ species and cultivars (Long et al., 1999). Northeast China comprises three provinces, Heilongjiang, Jilin, and Liaoning, and some studies of Lilium germplasm have been conducted in this area (Wang and Tang, 1980).

Based on morphological and physiological characteristics, Lilium plants in China have been assigned to the sections 
Table 1. Materials used for karyotype and FISH analysis of Lilium species native to China (Comber, 1949).

\begin{tabular}{|c|c|}
\hline Lilium species & Location in China \\
\hline \multicolumn{2}{|l|}{ Section Leucolirion } \\
\hline L. brownii (Hubei) & Shennongjia, Hubei (lat. $31^{\circ} 28^{\prime} \mathrm{N}$, long. $110^{\circ} 23^{\prime} \mathrm{E}$ ) \\
\hline L. brownii (Liaoning) & Dandong, Liaoning (lat. $40^{\circ} 07^{\prime} \mathrm{N}$, long. $124^{\circ} 19^{\prime} \mathrm{E}$ ) \\
\hline L. brownii (Guangxi) & Nandan, Guangxi (lat. $25^{\circ} 06^{\prime} \mathrm{N}$, long. $107^{\circ} 27^{\prime} \mathrm{E}$ ) \\
\hline L. leucanthum & Qianjiang, Chongqing (lat. $29^{\circ} 26^{\prime} \mathrm{N}$, long. $108^{\circ} 42^{\prime} \mathrm{E}$ ) \\
\hline L. longiflorum & Kaili, Guizhou (lat. $24^{\circ} 41^{\prime} \mathrm{N}$, long. $107^{\circ} 50^{\prime} \mathrm{E}$ ) \\
\hline L. regale & Maoxian, Sichuan (lat. $31^{\circ} 51^{\prime} \mathrm{N}$, long. $103^{\circ} 37^{\prime} \mathrm{E}$ ) \\
\hline L. sargentiae & Baoxing, Sichuan (lat. $30^{\circ} 33^{\prime} \mathrm{N}$, long. $102^{\circ} 42^{\prime} \mathrm{E}$ ) \\
\hline L. sulphureum & Baoxing, Sichuan (lat. $30^{\circ} 33^{\prime} \mathrm{N}$, long. $102^{\circ} 42^{\prime} \mathrm{E}$ ) \\
\hline \multicolumn{2}{|l|}{ Section Sinomartagon } \\
\hline L. henryi & Kaili, Guizhou (lat. $26^{\circ} 37^{\prime} \mathrm{N}$, long. $107^{\circ} 56^{\prime} \mathrm{E}$ ) \\
\hline L. jinfushanense & Jinfo Mountain area, Chongqing (lat. $29^{\circ} 06^{\prime} \mathrm{N}$, long. $107^{\circ} 11^{\prime} \mathrm{E}$ ) \\
\hline L. pumilum & Taibai Mountain, Shanxi (lat. $34^{\circ} 07^{\prime} \mathrm{N}$, long. $107^{\circ} 53^{\prime} \mathrm{E}$ ) \\
\hline L. speciosum & Lushan Mountain area, Jiangxi (lat. $29^{\circ} 39^{\prime} \mathrm{N}$, long. $115^{\circ} 59^{\prime} \mathrm{E}$ ) \\
\hline L. lancifolium & Yixing, Jiangsu (lat. $31^{\circ} 21^{\prime} \mathrm{N}$, long. $119^{\circ} 46^{\prime} \mathrm{E}$ ) \\
\hline \multicolumn{2}{|l|}{ Section Lophophorum } \\
\hline L. concolor & Yichun, Heilongjiang (lat. $47^{\circ} 43^{\prime} \mathrm{N}$, long. $128^{\circ} 53^{\prime} \mathrm{E}$ ) \\
\hline \multicolumn{2}{|l|}{ Section Martagon } \\
\hline L. tsingtauense & Haiyang, Shandong (lat. $36^{\circ} 51^{\prime} \mathrm{N}$, long. $121^{\circ} 06^{\prime} \mathrm{E}$ ) \\
\hline
\end{tabular}

Cytogenetic studies are useful for plant taxonomy. Cytogenetic investigations of some Lilium interspecific hybrids have received considerable attention (Lim et al., 2000, 2001a, 2001b; Noda, 1971), but cytogenetic studies are still not generally performed for Chinese Lilium species, and the reports are not always consistent. The karyotype of L. dauricum from the Mao'er Mountain region of Heilongjiang Province was 4B in a report by Yang et al. (1996), but it was reported as 3 A by Rong et al. (2009). Similarly, the karyotype of $L$. davidii was reported as $3 \mathrm{~A}$ in a study by Dai et al. (2006) but as 3B in a report by Xie and Wu (1993). Yu et al. (2000) analyzed the karyotypes of seven different L. sargentiae populations in China. The results showed that for all seven populations, all karyotypes belonged to Stebbin's type 3B. The karyotypic formulas showed only

Table 2. Types of chromosomes in plants defined based on centromere location and the arm ratio ( $\mathrm{Li}$ and Chen, 1985).

\begin{tabular}{llc}
\hline Arm ratio $^{z}$ & Location of centromere & Abbreviation \\
\hline 1 & Median point & $M$ \\
$1.01-1.70$ & Median region & $m$ \\
$1.71-3.00$ & Submedian region & $s m$ \\
$3.01-7.00$ & Subterminal region & $s t$ \\
$>7.00$ & Terminal region & $t$ \\
\hline
\end{tabular}

${ }^{\mathrm{z}}$ Length of the long arm/length of the short arm.

Table 3. Lilium karyotypes defined by the ratio of the length of the longest chromosome to that of the shortest chromosome $(\mathrm{Lt} / \mathrm{St})$, and the percentage of chromosomes with an arm ratio of greater than 2:1 (Stebbins, 1971).

\begin{tabular}{lcccc}
\hline & \multicolumn{4}{c}{ Chromosomes with an arm ratio $>2: 1(\%)$} \\
\cline { 2 - 5 }$L t / S t$ & 0 & $0.01-0.5$ & $0.51-0.99$ & 1 \\
\hline$<2: 1$ & $1 \mathrm{~A}$ & $2 \mathrm{~A}$ & $3 \mathrm{~A}$ & $4 \mathrm{~A}$ \\
$2: 1$ to $4: 1$ & 1B & $2 \mathrm{~B}$ & $3 \mathrm{~B}$ & $4 \mathrm{~B}$ \\
$>4: 1$ & 1C & 2C & $3 \mathrm{C}$ & $4 \mathrm{C}$ \\
\hline
\end{tabular}

Leucolirion, Sinomartagon, Martagon, and Lophophorum (Wang and Tang, 1980). Because of their similar morphological characteristics, especially conserved flower shapes in distantly related species, identification of Lilium species using only external morphology is difficult. For example, L. henryi, which has previously been classed into section Sinomartagon based on its morphological characteristics, matched those of $L$. regale and $L$. sulphureum quite well in a C-band pattern, and its transfer to section Leucolirion has been proposed. This is consistent with results from interspecies hybrids between $L$. henryi and L. regale (and related species), which are reportedly fertile (Smyth et al., 1989). However, L. henryi has always previously been assigned to section Sinomartagon. a few variations: relative length, arm ratio, and secondary constitution number and distribution. Members of the same species appear to always show similar karyotypes, with minor differences reflecting their distribution.

In addition to karyotypes, FISH is another technique providing chromosomal markers that show the positions of specific genes, thereby permitting chromosomal identification. The use of FISH with $5 \mathrm{~S}$ and $45 \mathrm{~S}$ rDNA probes has provided molecular cytogenetic markers for the identification of somatic chromosomes in different Lilium species (Lee et al., 2014; Liu et al., 2006; Nguyen et al., 2016; Sultana et al., 2010, 2011). FISH has been used for the verification of Lilium hybrids for many years (Lee et al., 2014; Lim et al., 2001a, 2001b; Sultana et al., 2011). However, the FISH analysis of rRNA genes is still rarely used for identifying Chinese Lilium species except in a report by Liu et al. (2016). The objective of this work was to compare the karyotypes and the 45S rRNA gene locations among 15 Lilium species from China.

\section{Materials and Methods}

Plant materials. Bulbs of 15 Lilium species were collected from different locations, as shown in Table 1 and were preserved vegetatively as clones at Nanjing Forestry University. Twelve of the 15 species were distributed between latitudes $34^{\circ} 07^{\prime} \mathrm{N}$ and $25^{\circ} 06^{\prime} \mathrm{N}$. L. brownii was the most widespread species, showing high adaptability in China. Three similar variants were collected from Nandan, Guangxi, China (lat. $25^{\circ} 06^{\prime} \mathrm{N}$, long. $107^{\circ} 27^{\prime} \mathrm{E}$ ); Shennongjia, Hubei, China (lat. $31^{\circ} 28^{\prime} \mathrm{N}$, long. $110^{\circ} 23^{\prime} \mathrm{E}$ ); and Dandong, Liaoning, China (lat. $40^{\circ} 07^{\prime} \mathrm{N}$, long. $124^{\circ} 19^{\prime} \mathrm{E}$ ).

KARYOTYPE ANALYSIS OF MITOTIC CHROMOSOMES. Root tips (1.5-2 cm in length) were pretreated with $0.7 \mathrm{mmol} \cdot \mathrm{L}^{-1}$ cyclohexamide at room temperature for $8 \mathrm{~h}$, washed with distilled water, and fixed in Carnoy's fixative (3:1 ethanol : acetic acid $\mathrm{v} / \mathrm{v}$ ) (Gill et al., 1991) for $24 \mathrm{~h}$ at room temperature. For chromosome preparations, the root tips were rinsed thoroughly 
and treated with an enzyme mixture $(3 \%$ pectolyase and $3 \%$ cellulase in $150 \mathrm{~mm}$ citrate buffer) at $37^{\circ} \mathrm{C}$ for $2.5 \mathrm{~h}$. Macerated root tips were placed on the slides, $20 \mu \mathrm{L}$ of $60 \%$ acetic acid was added, and the slides were put on the slide heater (TPJ-A; Huahai, Hangzhou, China) at $55^{\circ} \mathrm{C}$, smeared with a dissecting needle, washed with Carnoy's fixative, and air dried.

Slides used for karyotype analysis were dyed with carbol fuchsin (Carr and Walker, 1961) (30\%, 1-3 min) and then at least 10 metaphases nuclei were observed and photographed using a microscope with a $60 \times$ objective (BX51; Olympus, Tokyo, Japan). Chromosome length was recorded as the average of five metaphases. The karyotype analysis was performed according to Li and Chen (1985), as shown in Table 2. Karyotyping was performed in accordance with Stebbins (1971), as shown in Table 3.

FISH ANALYSIS. Probe labeling and FISH of the Lilium plants were performed according to a previous report (Liu et al., 2016) as follows. The slides were prepared as for the karyotype analysis. The cloned 45S rDNA from rice (Oryza sativa) was labeled with fluorescein-12-dUTP by nick translation. To label the probe, $50 \mu \mathrm{L}$ of labeling mixture, containing $5 \mu \mathrm{L}$ of $10 \times$ buffer, $1.5 \mu \mathrm{g}$ of $45 \mathrm{~S}$ rDNA, $5 \mu \mathrm{L}$ of deoxynucleotide mix ( $0.4 \mathrm{~mm}$ deoxyadenosine triphosphate, $0.4 \mathrm{~mm}$ deoxycytidine triphosphate, $0.4 \mathrm{~mm}$ deoxyguanosine triphosphate, $0.4 \mathrm{~mm}$ deoxythymidine triphosphate), 4 U DNA Polymerase I, 0.002 U DNase I, and 1 nm fluorescein-12-dUTP (Roche, Mannheim, Germany), was reacted at $15{ }^{\circ} \mathrm{C}$ for $2 \mathrm{~h}$ and held at $4{ }^{\circ} \mathrm{C}$ in a PCR instrument (Sultana et al., 2011). Then, $5 \mu \mathrm{L}$ of ethylenediaminetetraacetic acid $(0.5 \mathrm{M}, \mathrm{pH} 8.0)$ was added to stop the reaction. The FISH procedure was adopted from Lim et al. (2005). First, the chromosomes were pretreated with 100 $\mu \mathrm{g} \cdot \mathrm{mL}^{-1}$ DNase-free RNase (Qcbic S\&T, Shanghai, China) dissolved in $2 \times$ saline sodium citrate (SSC) for $1 \mathrm{~h}$ at $37^{\circ} \mathrm{C}$, treated with pepsin $\left[5 \mu \mathrm{g} \cdot \mathrm{mL}^{-1}\right.$ (Amresco, Solon, OH)] for $10 \mathrm{~min}$ at $37{ }^{\circ} \mathrm{C}$, and fixed in $4 \%$ paraformaldehyde (Sigma-Aldrich, St. Louis, MO) for $10 \mathrm{~min}$ at room temperature. The slides were washed in $2 \times$ SSC for 5 min, dehydrated in an ethanol gradient $(70 \%$, $95 \%, 100 \%$ ), and air-dried. The hybridization mixture consisted of $50 \%$ formamide, $10 \%$ sodium dextran sulfate, $2 \times \mathrm{SSC}, 0.5 \mu \mathrm{L}$ of sperm DNA per slide $\left(10 \mathrm{mg} \cdot \mathrm{mL}^{-1}\right)$, and DNA probe (100 ng per slide). The chromosomes were denatured in $70 \%$ formamide at $78{ }^{\circ} \mathrm{C}$ for $70 \mathrm{~s}$, dehydrated in a prechilled $\left(-20{ }^{\circ} \mathrm{C}\right)$ ethanol gradient $(70 \%, 95 \%$, and $100 \%)$, and air-dried. The DNA probes were denatured at $100{ }^{\circ} \mathrm{C}$ for $10 \mathrm{~min}$ and then cooled on ice. Next, $15 \mu \mathrm{L}$ of hybridization mix was added to each slide and covered with a cover glass, and the slides were kept in a moist chamber overnight at $37^{\circ} \mathrm{C}$. After hybridization, the slides were washed at $42{ }^{\circ} \mathrm{C}$ in $2 \times \mathrm{SSC}, 50 \%$ formamide, and $2 \times \mathrm{SSC}$ for $10 \mathrm{~min}$ each, followed by a 5 -min wash in 3.01 and 7.00 .
$1 \times$ phosphate buffered saline (PBS). The slides were then counterstained with $5 \mathrm{mg} \cdot \mathrm{mL}^{-1}$ propidium iodide for $4 \mathrm{~min}$, washed three times with $1 \times$ PBS for $\approx 20$ s each time, coated with $10 \mu \mathrm{L}$ mounting medium (VectaShield; Vector Laboratories, Burlingame, CA) and then covered with $20 \times 20$-mm glass coverslips. Hybridization signals were observed using a fluorescence microscope (BX51; Olympus). At least 10 metaphase and 10 interphase cells were examined per sample. Selected

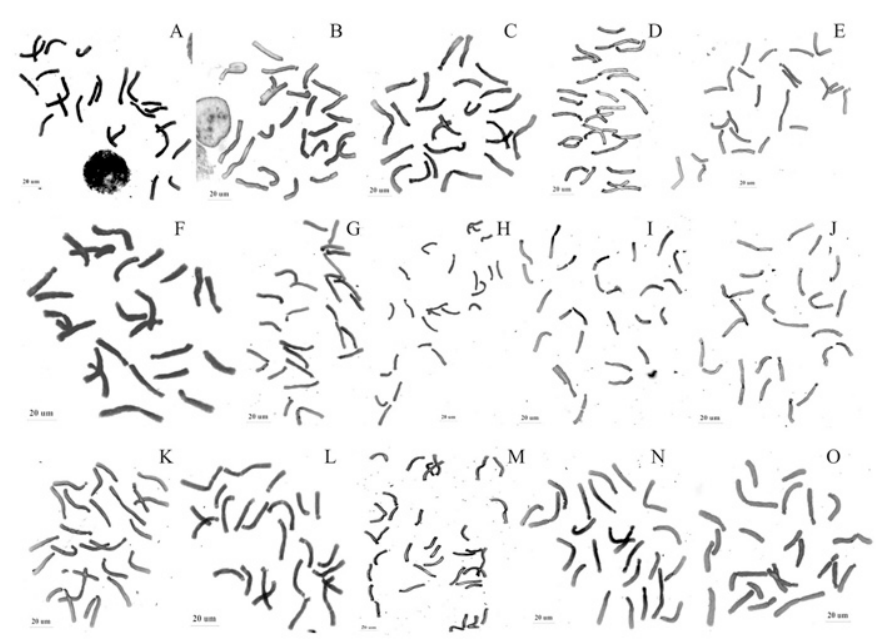

Fig. 1. Carbol fuchsin-stained mitotic metaphase chromosomes of 15 Lilium species native to China: (A) L. brownii (Hubei), (B) L. brownii (Liaoning), (C) L. brownii (Guangxi), (D) L. leucanthum, (E) L. longiflorum, (F) L. regale, (G) L. sargentiae, (H) L. sulphureum, (I) L. henryi, (J) L. jinfushanense, (K) L. pumilum, (L) L. speciosum, (M) L. lancifolium, (N) L. concolor, (O) L. tsingtauense.

Table 4. Karyotype formula, ratio of the length of the longest chromosome to that of the shortest chromosome $(\mathrm{Lt} / \mathrm{St})$, and types of 15 Lilium species native to China.

\begin{tabular}{|c|c|c|c|}
\hline Lilium species & Karyotype formula $^{z}$ & $\mathrm{Lt} / \mathrm{St}$ & Type \\
\hline \multicolumn{4}{|l|}{ Section Leucolirion } \\
\hline L. brownii (Hubei) & $2 n=2 x=24=4 m+12 s t+8 t$ & 1.9 & $3 \mathrm{~A}^{\mathrm{y}}$ \\
\hline L. brownii (Liaoning) & $2 n=2 x=24=4 m+14 s t+6 t$ & 2.01 & $3 \mathrm{~B}^{\mathrm{x}}$ \\
\hline L. brownii (Guangxi) & $2 n=2 x=24=4 m+16 s t+4 t$ & 2.01 & $3 \mathrm{~B}$ \\
\hline L. leucanthum & $2 n=2 x=24=2 m+2 s m+18 s t+2 t$ & 2.15 & $3 \mathrm{~B}$ \\
\hline L. longiflorum & $2 n=2 x=24=4 m+12 s t+8 t$ & 1.86 & $3 \mathrm{~A}$ \\
\hline L. regale & $2 n=2 x=24=4 m+10 s t+10 t$ & 2.14 & $3 \mathrm{~B}$ \\
\hline L. sargentiae & $2 n=2 x=24=2 m+2 s m+6 s t+14 t$ & 2.14 & $3 \mathrm{~B}$ \\
\hline L. sulphureum & $2 n=2 x=24=2 m+2 s m+14 s t+6 t$ & 1.92 & $3 \mathrm{~A}$ \\
\hline \multicolumn{4}{|l|}{ Section Sinomartagon } \\
\hline L. henryi & $2 n=2 x=24=2 m+2 s m+10 s t+10 t$ & 2.01 & $3 \mathrm{~B}$ \\
\hline L. jinfushanense & $2 n=2 x=24=2 m+2 s m+4 s t+16 t$ & 1.8 & $3 \mathrm{~A}$ \\
\hline L. pumilum & $2 n=2 x=24=2 m+2 s m+14 s t+6 t$ & 1.93 & $3 \mathrm{~A}$ \\
\hline L. speciosum & $2 n=2 x=24=2 m+2 s m+10 s t+10 t$ & 2.11 & $3 \mathrm{~B}$ \\
\hline L. lancifolium & $2 n=3 x=36=3 m+3 s m+18 s t+12 t$ & 1.91 & $3 \mathrm{~A}$ \\
\hline \multicolumn{4}{|l|}{ Section Lophophorum } \\
\hline L. concolor & $2 n=2 x=24=4 m+20 s t$ & 1.80 & $3 \mathrm{~A}$ \\
\hline \multicolumn{4}{|l|}{ Section Martagon } \\
\hline L. tsingtauense & $2 n=2 x=24=4 m+8 s t+12 t$ & 2.29 & $3 \mathrm{~B}$ \\
\hline
\end{tabular}

$\overline{\mathrm{z}_{m}}=$ chromosome with arm ratio between 1.01 and 1.70, st $=$ chromosome with arm ratio between 3.01 and $7.00, t=$ chromosome with arm ratio above $7.00, \mathrm{sm}=$ chromosome with arm ratio between

${ }^{\mathrm{y}} L t / S t<2: 1$ (percentage of chromosomes with an arm ratio $>2: 1$ is between $51 \%$ and $99 \%$ ).

${ }^{\mathrm{x}} \mathrm{Lt} / \mathrm{St}$ between $2: 1$ and $4: 1$. 
chromosome spreads from metaphase nuclei were photographed with a digital camera (DP72; Olympus).

\section{Results}

KARYOTYPE ANALYSIS. In comparison with a previous study of L. rosthornii (Liu et al., 2016), we used a chromosome protocol-based on smearing instead of squashing. From the chromosome images, we can see that the new method is more appropriate than the previous method. In particular, smearing was more effective than squashing at protecting chromosome morphology.

All Lilium species except $L$. lancifolium were diploid with chromosomes $2 n=2 X=24$ (Fig. 1). As shown in Table 4 and Figs. 1-3, 14 diploid species had 2 large metacentric chromosomes and 10 smaller acrocentric chromosomes. Chromosomes 9 and 10 of the three L. brownii samples had secondary constrictions (SCs) on their long arms. The only triploid species, L. lancifolium, also had two groups of $m$ or $s m$

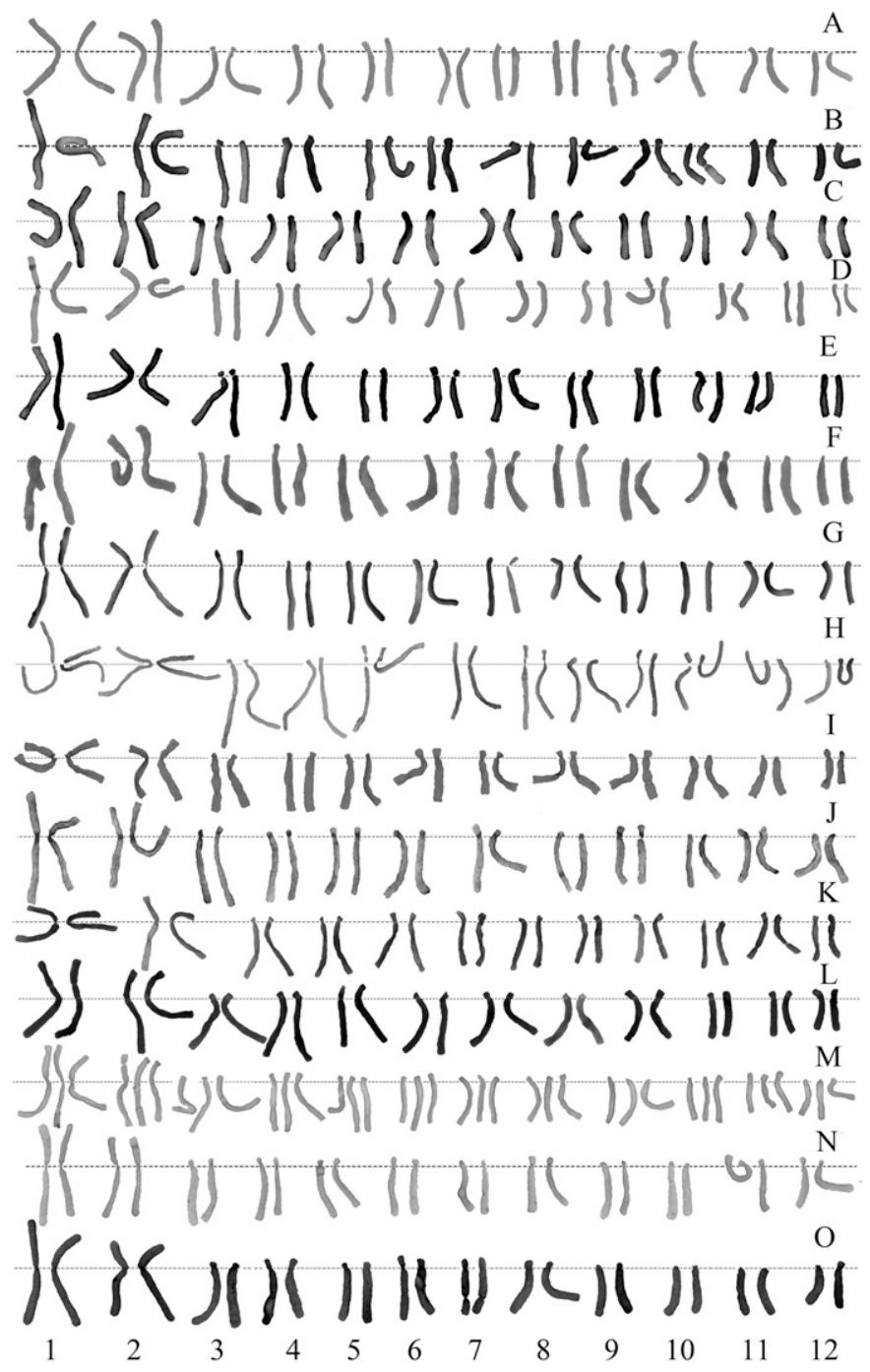

Fig. 2. Karyograms of the 15 Lilium species native to China: (A) L. brownii (Hubei), (B) L. brownii (Liaoning), (C) L. brownii (Guangxi), (D) L.

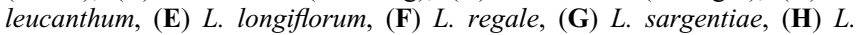
sulphureum, (I) L. henryi, (J) L. jinfushanense, (K) L. pumilum, (L) L. speciosum, (M) L. lancifolium, (N) L. concolor, (O) L. tsingtauense. chromosomes. The karyotypes of the 15 Lilium species could be divided into two groups: $3 \mathrm{~A}$ and $3 \mathrm{~B}$. Seven species, three from Leucolirion, three from Sinomartagon, and one from Lophophorum, were 3A, and the other eight species, five from Leucolirion, two from Sinomartagon, and one from Martagon, were $3 \mathrm{~B}$. The $\mathrm{Lt} / \mathrm{St}$ (ratio of the length of the longest chromosome to that of the shortest chromosome) was between 1.80 and 2.29 (Table 4), with the average exactly at 2.00, which is the dividing line between karyotypes $3 \mathrm{~A}$ and $3 \mathrm{~B}$. Thus, although the karyotypes of these 15 species were divided into $3 \mathrm{~A}$ and $3 \mathrm{~B}$, they showed little difference from each other.

FISH ANALYSIS. FISH was used to analyze the variability of $45 \mathrm{~S}$ rRNA gene loci on the somatic metaphase chromosomes of these 15 Chinese Lilium species. The result showed that $45 \mathrm{~S}$ rDNA loci were distributed in all the chromosomes (Figs. 3-5). The numbers of loci differed significantly among the 15 evaluated species. Among the diploid species, L. regale (Figs. $4 \mathrm{~F}$ and $5 \mathrm{~F}$ ) showed the highest number at 12, and others showed 6,8 , or 10 loci. L. lancifolium $(2 n=3 X=36)$, the only triploid species, showed 15 45S rRNA gene loci (Figs. 3M, 4M, and $5 \mathrm{M})$. In addition to the differences in the numbers of loci, we observed differences in the placement of the gene loci on the chromosomes.

In L. brownii (Hubei), L. brownii (Liaoning), and $L$. brownii (Guangxi), three pairs of $45 \mathrm{~S}$ rDNA signals were recorded on the centromeric region of chromosome 3 and the long arms of chromosomes 9 and 10 (Figs. 3A-C, 4A-C, and $5 \mathrm{~A}-\mathrm{C}$ ), which were just the secondary construction area (Fig. 2A-C). In L. leucanthum, four pairs of signals were observed on the centromeres of chromosomes 1, 2, 6, and 10 (Figs. 3D, 4D, and 5D). In L. longiflorum, six 45S rDNA signals were detected on the centromeric regions of chromosomes 3, 4, and 6 (Figs. 3E, 4E, and 5E). In L. regale, 10 of the $1245 \mathrm{~S}$ rDNA loci were observed on the centromeric regions of chromosomes 1, 2, 8, 9, and 10, and the other two were located on the long arm of chromosome 7 (Figs. 3F, 4F, and $5 \mathrm{~F})$. In L. sargentiae, eight paired signals were observed on the centromeres of chromosomes 1, 2, 8, and 11 (Figs. 3G, $4 \mathrm{G}$, and $5 \mathrm{G}$ ). In L. sulphureum, six of the eight $45 \mathrm{~S}$ rDNA loci were present on the centromeric regions of chromosomes 1,2, and 11, and the other two were located on the long arm of chromosome 4 (Figs. 3H, 4H, and 5H). In L. henryi, five signals were detected on the centromeric region of chromosome 1 , the long arm of chromosome 8 , and the long arm of chromosome 10 (Figs. 3I, 4I, and 5I). In L. jinfushanense, six of the eight $45 \mathrm{~S}$ rDNA signals were detected on the centromeric regions of the homologous chromosomes 1 , 3 , and 8 , and the other two were located on the long arms of chromosome 6 (Figs. 3J, 4J, and 5J). In L. pumilum, eight 45S rDNA signals were detected on the centromeric regions of chromosomes 1, 3, 4, and 6 (Figs. 3K, 4K, and 5K). In $L$. speciosum, ten $45 \mathrm{~S}$ rDNA loci were present on the centromeric regions of chromosomes 1, 5, 8, 11, and 12 (Figs. 3L, 4L, and 5L). In L. lancifolium, which was the only triploid species, $1545 \mathrm{~S}$ rDNA signals were detected on the short arm near the centromeric regions of chromosomes 1 and 3 , the long arms of chromosomes 6 and 11, and the short arm of chromosome 2 (Figs. 3M, 4M, and 5M). In L. concolor, 10 $45 \mathrm{~S}$ rDNA were detected on the centromeres of chromosomes $1,3,8$, and 10 and on the short arm of chromosome 2 (Figs. 3N, 4N, and 5N). In L. tsingtauense, eight 45S rDNA 


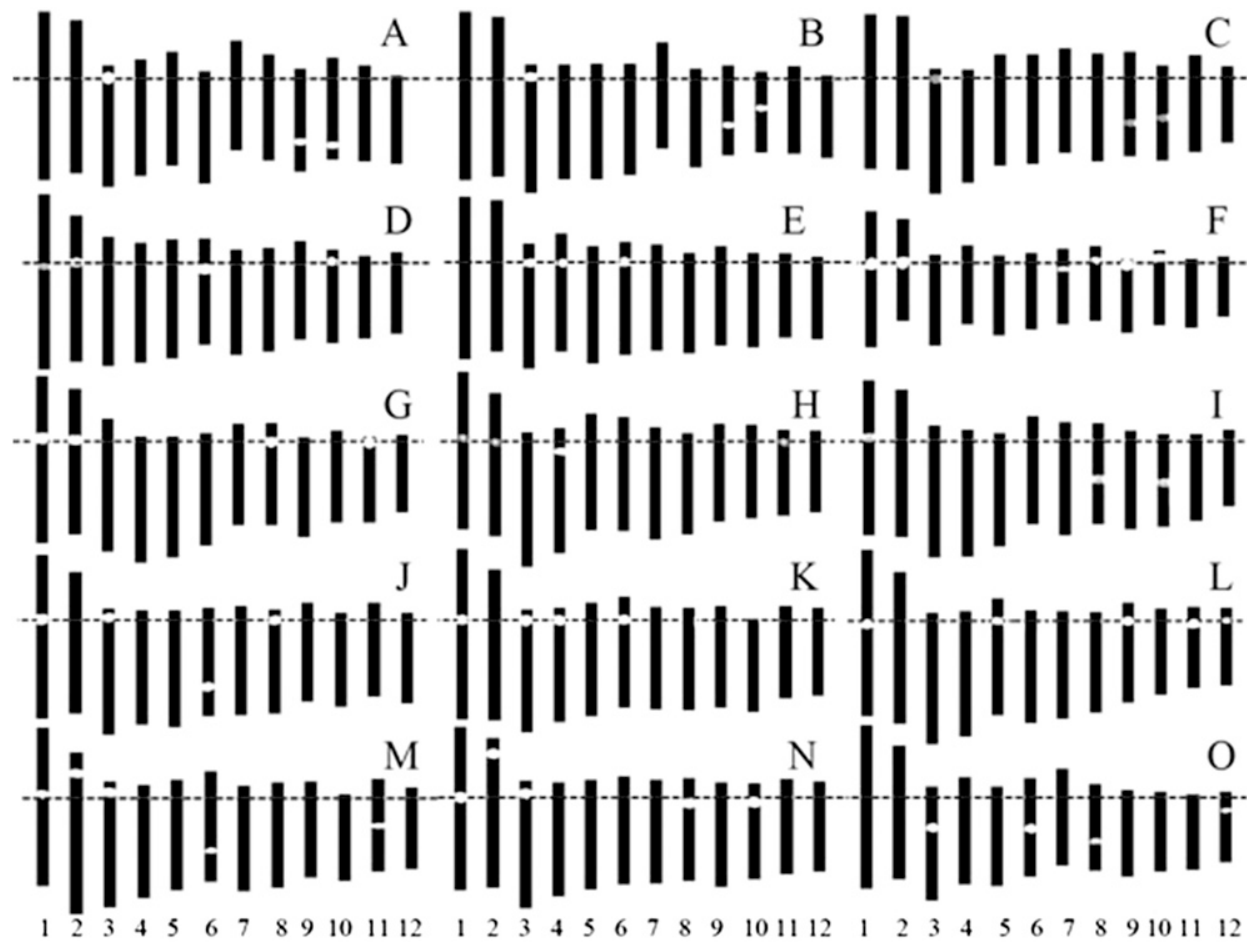

Fig. 3. Chromosome idiogram of 15 Lilium species native to China: (A) L. brownii (Hubei), (B) L. brownii (Liaoning), (C) L. brownii (Guangxi), (D) L. leucanthum, (E) L. longiflorum, (F) L. regale, (G) L. sargentiae, (H) L. sulphureum, (I) L. henryi, (J) L. jinfushanense, (K) L. pumilum, (L) L. speciosum, (M) L. lancifolium, (N) L. concolor, (O) L. tsingtauense.

loci were detected on the long arms of chromosomes $3,6,8$, and 12 (Figs. 3O, 4O, and 5O).

Loci show high polymorphism not only in number but also in their chromosomal locations. Most signals, $66.1 \%$ of the total, were located near the centromeric region of the chromosome. Another $28.2 \%$ of the loci were located on the long arm. Only seven loci, $\approx 5.6 \%$, were detected on the short arm. In 10 species, chromosome 1 showed $45 \mathrm{~S}$ rDNA loci on their centromeric regions. The other five species without signals on chromosome 1 all showed signals on chromosome 3 . The three L. brownii materials from the three different provinces showed very similar signal distributions.

\section{Discussion}

As one of the most important worldwide cut and potted flower crops, Lilium species are facing the threat of genetic erosion. Therefore, increasing attention has been paid to the conservation of Lilium resources (Zhou et al., 2012). The classification and identification of these resources are important for plant material preservation and utilization. Karyotype comparison analysis has long been used to describe chromosome patterns and evolution in some closely related groups (Stebbins, 1971).

Although we obtained clear figures for all materials, sometimes the constriction, especially the second constriction, was difficult to determine.

Members of the tribe Lilieae are similar in genome size and karyotype idiogram and have the same basic chromosome number (Stewart, 1947). Chinese Lilium species also showed similar karyotypes, 3A or 3B, and always only with two pairs of $m$ or $\mathrm{sm}$. The Lt/St values for Chinese Lilium species are close to
2.00 , which is the dividing line between $3 \mathrm{~A}$ and $3 \mathrm{~B}$. This has troubled some researchers in L. rosthornii karyotype separation. Liu et al. (2010) concluded that $L$. rosthornii belonged to 3B, Qing (2011) believed that it belonged to $3 \mathrm{~A}$, and Liu et al. (2016) considered it 3B. Although the karyotypes of Lilium species can be divided into $3 \mathrm{~A}$ and 3B, their karyotypes are similar, as demonstrated in Table 1.

In a previous study, FISH mapping using 45S rDNA probes in Korean Lilium species demonstrated that the $45 \mathrm{~S}$ rDNA loci were distributed across most chromosomes except chromosomes 8, 9, and 12 (Sultana et al., 2010). The sites of these loci were more variable in the Chinese Lilium species, with all chromosomes showing $45 \mathrm{~S}$ rDNA signals. Not all the $45 \mathrm{~S}$ rDNA loci were located in both homologue chromosomes. There were only five signals detected in L. henryi (Figs. 3I, 4I, and 5I). This phenomenon has only been observed in one other Chinese Lilium species, L. rosthornii (Liu et al., 2016), but Nguyen et al. (2016) also reported this phenomenon in several diploid L. lancifolium materials distributed in Korea. It has also been observed in other plant species (Liu et al., 2006). One possible explanation is that the tandem repeats of rDNA clusters permit chromosomal rearrangements that move the nuclear organization regions (NORs) to other chromosomes that did not previously have rDNA sequences. Nguyen et al. (2016) studied diploid and triploid L. lancifolium and reported that the 45S rRNA genes were located on chromosomes 1, 2, 4, 6,7 , and 11 , which did not conform to our results, particularly the loci located on chromosomes 3, 4, and 7. In our research, we did not find 45S rRNA signals on chromosomes 4 and 7 , but we found signals located on chromosome 3 , even though three of their materials were collected from the same region as ours. In a different study by Hwang et al. (2011), 45S rDNA was located on chromosomes 1, 2, 6, 7, and 11. However, in that report, they analyzed the chromosomes mainly by short arm length and not by chromosome total length as in our study. Thus, chromosome 7 in their research was stained, but the stained chromosome was chromosome 3 in our research; this is the reason for the disagreement. And we did not observed 45S rDNA loci on chromosome 4 of L. lancifolium. Hwang et al. (2011) also did not found 45S rDNA site on chromosome 4 in triploid $L$. lancifolium. But they found 45S rDNA signals on chromosome 4 in diploid $L$. lancifolium. These disagreements may indicate that $45 \mathrm{~S}$ rDNA site on chromosome 4 was not stable in $L$. lancifolium.

According to the ITS dataset, $L$. longiflorum and two $L$. brownii species had been classified into section Lilium Wang and Tang (Gao et al., 2012). In 45S rDNA FISH analysis, all three $L$. brownii materials and one $L$. longiflorum sample showed six signals. Other than L. tsingtauense, these are the 


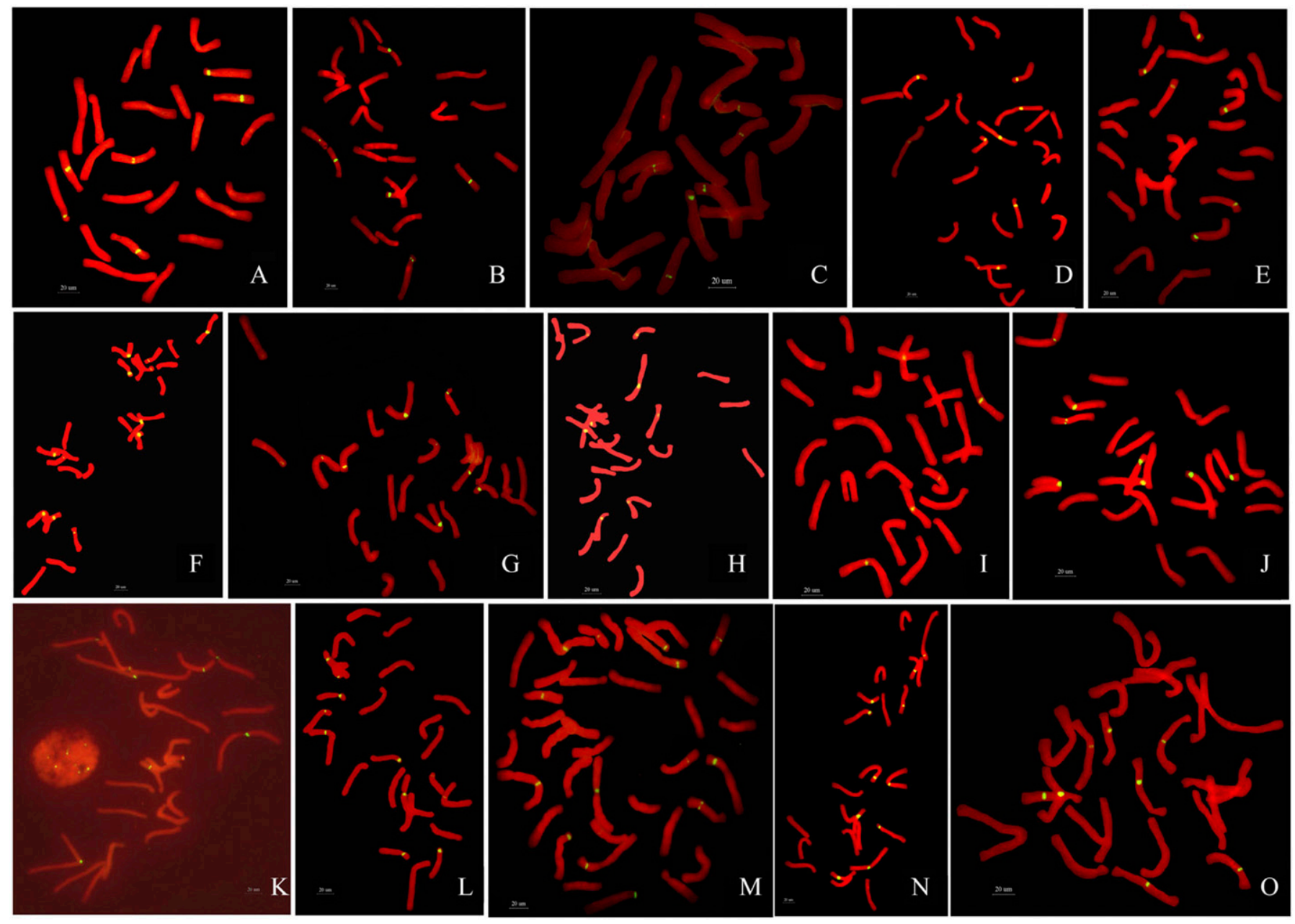

Fig. 4. Locations of $45 \mathrm{~S}$ rDNA on metaphase chromosomes of 15 Lilium species native to China: (A) L. brownii (Hubei), (B) L. brownii (Liaoning), (C) L. brownii (Guangxi), (D) L. leucanthum, (E) L. longiflorum, (F) L. regale, (G) L. sargentiae, (H) L. sulphureum, (I) L. henryi, (J) L. jinfushanense, (K) L. pumilum, (L) L. speciosum, (M) L. lancifolium, (N) L. concolor, $(\mathbf{O})$ L. tsingtauense.

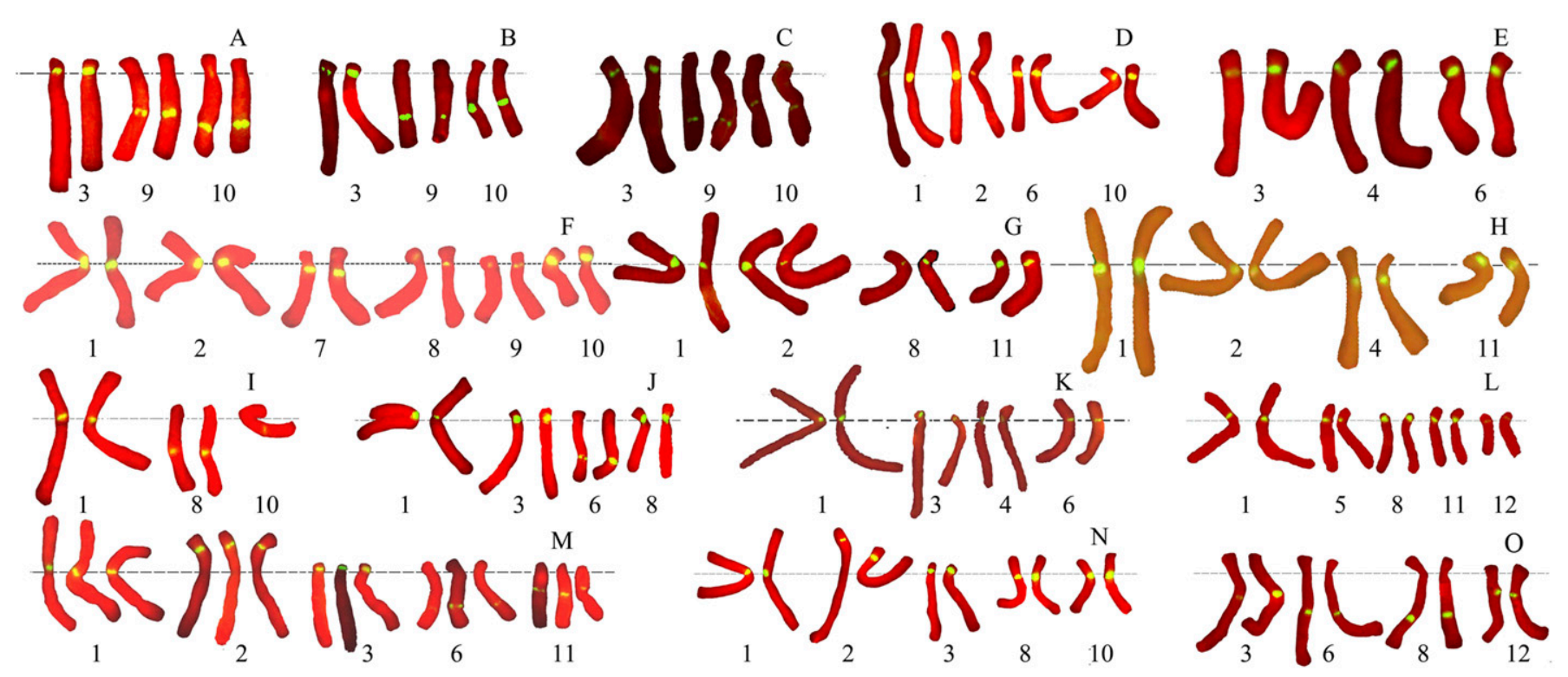

Fig. 5. Comparison of 45S rDNA location on the chromosomes from 15 Lilium species native to China: (A) L. brownii (Hubei), (B) L. brownii (Liaoning), (C) L. brownii (Guangxi), (D) L. leucanthum, (E) L. longiflorum, (F) L. regale, (G) L. sargentiae, (H) L. sulphureum, (I) L. henryi, (J) L. jinfushanense, (K) L. pumilum, (L) L. speciosum, (M) L. lancifolium, (N) L. concolor, $(\mathbf{O})$ L. tsingtauense. 
only four materials that did not show signals on chromosome 1 but did show signals on chromosome 3 . This demonstrated that our FISH results were partly consistent with the ITS results.

Interestingly, the three L. brownii species had different Chinese names and were obtained from widely distant locations (Table 1). According to Long et al. (1999), the only difference between L. brownii (Hubei) and L. brownii (Guangxi) was the leaf shape. The leaf shape of $L$. brownii (Hubei) was lanceolate to oval, and the leaf shape of L. brownii (Guangxi) was lanceolate or narrow lanceolate to lorate. In the present study, L. brownii samples from these locations showed very similar karyotype and FISH results. Gao et al. (2012) studied the karyotypes of 32 species of Lilium from China, including 10 of the materials we used. They divided $L$. brownii into a new section, Lilium Wang and Tang. This classification had also been proposed by Wang and Tang (1980). This was consistent with our results. We also found two pairs of chromosomes, 9 and 10, with SCs on their long arms where we also found the 45S rRNA gene loci. Noda (1971) concluded that the major difference among species of the genus Lilium corresponded to the number and position of SCs and the activity of the NORs. Therefore, this was additional evidence that these three $L$. brownii collections may be the same despite having different Chinese names. They were obtained from widely separated locations in China, Dandong, Liaoning (lat. $40^{\circ} 07^{\prime} \mathrm{N}$, long. $124^{\circ} 19^{\prime} \mathrm{E}$ ) to Nandan, Guangxi (lat. $25^{\circ} 06^{\prime} \mathrm{N}$, long. $\left.107^{\circ} 27^{\prime} \mathrm{E}\right)$. According to the information available online, Dandong, Liaoning, has a cold-temperate climate, and Nandan Guangxi has a mountain plateau climate. The annual average temperatures in these locations are $9{ }^{\circ} \mathrm{C}$ (Dandong, Liaoning), $16.9{ }^{\circ} \mathrm{C}$ (Nandan, Guangxi), and $12.9{ }^{\circ} \mathrm{C}$ (Shennongjia, Hubei). This indicated L. brownii can show extensive adaptability.

\section{Literature Cited}

Anderson, N.O. 1986. The distribution of the genus Lilium with reference to its evolution. Herbertia 42:31-50.

Carr, D.H. and J.E. Walker. 1961. Carbol fuchsin as a stain for human chromosomes. Stain Technol. 36:233-236.

Chen, H., X.L. Chen, L.Q. Chen, and X.X. Lu. 2007. Cryopreservation of shoot tips from in vitro plants of cut flower of lily (Lilium L.) by vitrification method. J. Plant Genet. Resources 8:170-173.

Comber, H.F. 1949. A new classification of the genus Lilium. Royal Hort. Soc. Lily Yrbk. 13:86-105.

Dai, X.H., Y.L. Zhang, and L.X. Niu. 2006. Karyotypes of four Lilium species. Xibei Zhiwu Xuebao 26:50-55.

De Jong, P.C. 1974. Some notes on the evolution of lilies. North Amer. Lily Yrbk. 27:23-28.

Endlicher, S. 1836. Genera plantarum secundum ordines naturales disposita. Apud F. Beck Press, Vindobonae, Austria.

Gao, Y.D., S.D. Zhou, X.J. He, and J. Wan. 2012. Chromosome diversity and evolution in tribe Lilieae (Liliaceae) with emphasis on Chinese species. J. Plant Res. 125:55-69.

Gill, B.S., B. Friebe, and T.R. Endo. 1991. Standard karyotype and nomenclature system for description of chromosome bands and structural aberrations in wheat (Triticum aestivum). Genome 34: 830-839.

Hwang, Y.J., H.H. Kim, J.B. Kim, and K.B. Lim. 2011. Karyotype analysis of Lilium tigrinum by FISH. Hort. Environ. Biotechnol. 52:292-297.

Lee, H.I., A. Younis, Y.J. Hwang, Y.I. Kang, and K.B. Lim. 2014. Molecular cytogenetic analysis and phylogenetic relationship of $5 \mathrm{~S}$ and $45 \mathrm{~S}$ ribosomal DNA in sinomartagon Lilium species by fluorescence in situ hybridization (FISH). Hort. Environ. Biotechnol. 55:514-523.

Li, M.X. and R.Y. Chen. 1985. A suggestion on the standardization of karyotype analysis in plants. J. Wuhan Bot. Res. 3:297-302.

Lim, K.B., J.D. Chung, B.C.E. van Kronenburg, M.S. Ramanna, J.H. de Jong, and J.M. van Tuyl. 2000. Introgression of Lilium rubellum Baker chromosomes into L. longiflorum Thunb.: A genome painting study of the $\mathrm{F}_{1}$ hybrid, $\mathrm{BC}_{1}$ and $\mathrm{BC}_{2}$ progenies. Chromosome Res. $8: 119-125$.

Lim, K.Y., R. Matyasek, A. Kovarik, J. Fulnecek, and A.R. Leitch. 2005. Molecular cytogenetics and tandem repeat sequence evolution in the allopolyploid Nicotiana rustica compared with diploid progenitors N. paniculata and N. undulate. Cytogenet. Genome Res. 109:298-309.

Lim, K.B., J. Wennekes, J.H. de Jong, E. Jacobsen, and J.M. van Tuyl. 2001a. Karyotype analysis of Lilium longiflorum and Lilium rubellum by chromosome banding and fluorescence in situ hybridisation. Genome 44:911-918.

Lim, K.B., J. Wennekes, J.H. De Jong, E. Jacobsen, and J.M. van Tuyl. 2001b. Karyotype analysis of Lilium longiflorum and Lilium rubellum by chromosome banding and fluorescence in situ hybridization. Genome 44:911-918.

Liu, B., C.B. Chen, X.L. Li, R.Y. Chen, and W.Q. Song. 2006. Physical mapping of $45 \mathrm{~S}$ rDNA on metaphase chromosomes in several plant species. Acta Sci. Nat. Univ. Nankaiensis 39:96102.

Liu, G.X., Y. Lan, H.Y. Xin, F.R. Hu, Z.H. Wu, J.S. Shi, and M.L. Xi. 2016. Cytogenetic analysis of Lilium rosthornii Diels. J. Amer. Soc. Hort. Sci. 141:444-448.

Liu, H.M., L. Zhi, L.H. Zhao, S.Z. Sui, and M.Y. Li. 2010. Karyotype analysis of four wild Lilium species. J. Plant Genet. Resources 11:469-473.

Long, Y.Y., J.Z. Zhang, and L.N. Zhang. 1999. Lily: The king of bulb flower. Jindun Press, Beijing, China.

Mabberley, D.J. 1990. The plant-book. Cambridge Univ. Press, Cambridge, United Kingdom.

McRae, E.A. 1998. Lilies: A guide for grower and collectors. Timber Press, Portland, OR.

Nguyen, T.X., S.I. Lee, R. Rai, N.S. Kim, and J.H. Kim. 2016. Ribosomal DNA locus variation and REMAP analysis of the diploid and triploid complexes of Lilium lancifolium. Genome 59:551-564.

Noda, S. 1971. Cytogenetic studies on the hybrid lilies. I. Occurrences of binucleate cells in PMC and triploid variety. Bot. Mag. Tokyo 84:399-409.

Qing, Q.J. 2011. Karyotypes and genetic variations in 9 species of Lilium. Sichuan Agr. Univ., Chengdu, China, MS Diss.

Rong, L.P., J.J. Lei, Y. Zhen, and Y.F. Gao. 2009. Study on karyotypes of Lilium species native to northeast China. J. Jilin Agr. Univ. 31:711-716.

Smyth, D.R., K. Kongsuwan, and S. Wisdharomn. 1989. A survey of C-band patterns in chromosomes of Lilium (Liliaceae). Plant Syst. Evol. 163:53-69.

Stebbins, G.L. 1971. Chromosomal evolution in higher plants. Edward Arnold, London, United Kingdom.

Stewart, R.N. 1947. The morphology of somatic chromosomes in Lilium. Amer. J. Bot. 34:9-26.

Sultana, S., J.W. Bang, and H.W. Choi. 2011. Organization of the 5S rRNA gene units in Korean Lilium species. Genes Genomes 33:251257.

Sultana, S., S.H. Lee, J.W. Bang, and H.W. Choi. 2010. Physical mapping of rRNA gene loci and inter-specific relationships in wild Lilium distributed in Korea. J. Plant Biol. 53:433-443.

Wang, F.Z. and J. Tang. 1980. The flora of China. Vol. 14. Sci. Publishing House, Beijing, China.

Wu, X.W., S.F. Li, L. Xiong, Y.H. Qu, Y.P. Zhang, and M.T. Fan. 2006. Distribution situation and suggestion on protecting wild lilies in Yunnan province. Plant Genet. Resour. 7:327-330. 
Xie, X.Y. and Q.A. Wu. 1993. The determination of karyotype and isoesterase on triploid Lilium davidii. Acta Botanica Yunnanica 15:57-60.

Yang, L.P., B. Ding, X.H. Liu, and X.F. Zhang. 1996. Cytogenetic diversity in Lilium L. in northeast China. J. Northeast For. Univ. 24:19-23.

Yu, H., H.X. Wang, and D. You. 2000. Study on chromosomal morphology in populations of Lilium sargenttiae wilson. J. Yunnan Univ. (Natural Sci.) 22:60-67.
Zhang, Y.Q., X.X. Li, Q. Ma, H.P. Wang, and D. Shen. 2004. Preliminary study on vitrification cryopreservation technology of edible lily germplasm. China Vegetables 4:11-13.

Zhou, X.R., L.P. Yang, and W. Zhang. 2012. Investigation and evaluation of wild lily resources in Chongqing. J. Plant Genet. Resources 13:357-362.

Zonneveld, B.J.M., I.J. Leitch, and M.D. Bennett. 2005. First nuclear DNA amounts in more than 300 angiosperms. Ann. Bot. (Lond.) 96:229-244. 